\title{
PubChem: atom environments for molecule standardization
}

\author{
Volker Hähnke*, Evan E Bolton, Stephen H Bryant \\ From 8th German Conference on Chemoinformatics: 26 CIC-Workshop \\ Goslar, Germany. 11-13 November 2012
}

PubChem is an open repository for molecular structures, their properties and biological activities [1]. The number of deposited structures has been steadily increasing since its creation in 2004. Today, it contains more than 92 million substances (PubChem Substance) with 32 million unique small molecules (PubChem Compound). Consequently, visual inspection of every structure and correction of errors by hand to detect structure equivalencies and to ensure data quality are not feasible. Efficient and reliable automated methods for standardization are necessary during the registration process to compensate for alternating representations of as well as errors and artifacts in (sub)structure representations caused by diverging business rules, personal preferences, data format conversion, disagreements between aromaticity definitions and automated library generation. At PubChem, we are developing a new standardization approach that is based on rules for atom environment transformation. Those rules are obtained from a statistical analysis of atom environment transformations observed with a reference workflow combining chemical reasonability checks, valence filters, canonical tautomer determination and aromaticity normalization. Additional atom environment mappings are provided by hand curation. In the first application of our technique to PubChem we concentrate on purely organic compounds. Those represent $97 \%$ of the deposited structures and account for the majority of atom environments as well. Here, we present the first results obtained with our approach, highlighting the methodology, challenges, benefits and future possibilities.

Published: 22 March 2013

\footnotetext{
* Correspondence: volker.hahnke@nih.gov National Center for Biotechnology Information, National Library of Medicine, National Institutes of Health, Department of Health and Human Services, Bethesda, Maryland, 20894, USA
}

(C) 2013 Hähnke et al.; licensee BioMed Central Ltd. This is an Open Access article distributed under the terms of the Creative Commons Attribution License (http://creativecommons.org/licenses/by/2.0), which permits unrestricted use, distribution, and reproduction in any medium, provided the original work is properly cited.
Reference

Bolton E, Wang Y, Thiessen PA, Bryant SH: PubChem: Integrated Platform of Small Molecules and Biological Activities. In Annual Reports in Computational Chemistry, Volume 4, Chapter 12. Oxford:Elsevier;Wheeler RA, Spellmeyer DC 2008:217-241.

doi:10.1186/1758-2946-5-S1-P38

Cite this article as: Hähnke et al:: PubChem: atom environments for molecule standardization. Journal of Cheminformatics 2013 5(Suppl 1):P38.

\section{Publish with ChemistryCentral and every} scientist can read your work free of charge

"Open access provides opportunities to our colleagues in other parts of the globe, by allowing anyone to view the content free of charge."

W. Jeffery Hurst, The Hershey Company.

- available free of charge to the entire scientific community

- peer reviewed and published immediately upon acceptance

- cited in PubMed and archived on PubMed Central

- yours - you keep the copyright

Submit your manuscript here:

http://www.chemistrycentral.com/manuscript/

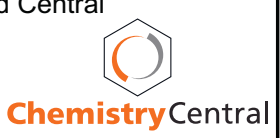

\section{() Chemistry Central}

